\title{
Emerging Technologies (ETs) in Education: A Systematic Review of the Literature Published between 2006 and 2016
}

\author{
https://doi.org/10.3991/ijet.v12i05.6939 \\ Edgar Andrés Sosa Neira \\ University of Balearic Islands (UIB), Bogotá, Colombia \\ easosan@gmail.com \\ Jesus Salinas \\ University of Balearic Islands (UIB), Palma de Mallorca, Spain \\ jesus.salinas@uib.es \\ Barbara de Benito Crosetti \\ University of Balearic Islands (UIB), Palma de Mallorca, Spain \\ barbara.debenito@uib.es
}

\begin{abstract}
This study systematically reviews, classifies and synthesizes the research related to Emerging Technologies (ETs) in the field of formal education between 2006 and 2016, aiming to identify areas of uncertainty for future research. In addition, this study is a tool to guide teachers in their decision making when incorporating technologies in the classroom. The research approach was mixed and it analyzed 288 studies that met the inclusion criteria. Results show that all the studies aimed to improve and to transform the different educational processes through the incorporation of ETs. The most used methodology was qualitative research; the survey was the most widely used instrument; the most affected population was the students in the context of higher education; the competences to improve was critical thinking, followed by problem solving, collaborative work, creative thinking, and decision-making. Emerging Technologies (ETs) are contextual, adaptable, evolving, ubiquitous, disruptive, innovative, complementary and generate a degree of uncertainty, they can be complex, accessible, functional, easy to use, interactive and it found that Web 2.0 technologies are the most used in the studies.
\end{abstract}

Keywords-Emerging Technologies, Education, Learning, Teaching

\section{Introduction}

Technology can be defined as "a collection of systems designed to perform some functions", [1] at a certain time and place, meaning that it constructs and adapts artifacts or tools in order to facilitate the daily life of human beings. Therefore, incor- 
porating technologies in the classroom is not something new; in fact, teachers have always used technology to support their teaching and learning processes.

In recent years, these technologies have been given various names; such as Information and Communication Technologies (ICT), Technologies in Education, Digital Technologies, New Technologies of Information and Communication (NTIC), Technologies of Learning and Knowledge, Technologies for Empowerment and Participation and Emerging Technologies (ETs). Without having to define each one, it is well known that all of them aim to improve educational processes.

The term of ETs was used for this review and it was conceptualized based on the contributions of several authors; such as Day and Schoemarker [2]; Velesiatnos [3]; Rotolo et al. [4] and Kabugo et al. [5]. They state that ETs should produce a radical change in learning processes. They also point out that not every new technology is necessarily emerging technology; for instance, there are "old" technologies that may be emerging in some contexts, they are disruptive technologies, which are adopted in the future and have a certain Degree of uncertainty and ambiguity.

According to the ideas mentioned above, ETs refers to resources, artifacts, tools, concepts and innovations associated with digital, that have a disruptive potential to transform or generate changes in the processes where they are used, regardless of whether these are new or old technologies.

This definition applies to any field, for example, in education, ETs are expected to transform or generate changes in different educational processes.

Thus, this work reviewed, classified and synthesized research related to the ET in the field of formal education based on the following questions:

- What are the objectives, methodologies, instruments of data collection and populations used in the studies related to the ETs in the field of formal education?

- What competences or skills do you want to improve when incorporating ETs in the classroom?

- What are the characteristics of ETs?

- What types of ETs are used in the field of education?

\section{Method}

The Systematic review and analysis was performed between May 2016 and early January 2017 using two electronic databases: Scopus and Web of Science. The review process followed 4 phases: in the first one, the inclusion and exclusion criteria were determined; in the second one, the search strategy was performed, in the third one, the search was debugged and the articles to read were chosen; and finally, in the fourth phase, the data was codified and analyzed in a quantitatively and qualitatively. Each phase will be described below. 


\subsection{Phase 1: Inclusion and exclusion criteria}

The inclusion criteria for the systematic review were: using Emerging Technologies in the educational field as a main condition; being part of the formal educational context; having the complete study and availability for later reading; publishing must have been made between January 2006 and December 2006; being part of the field of social sciences and the type of document must be an article, conference, review or article in press. The exclusion criteria were: journals or conference proceedings where fewer than three articles related to the subject of the review were published, and ETs being used for non-educational purposes.

\subsection{Phase 2: Search strategy}

The search strategy considered 2 major fields: Emerging Technologies and Education, based on terms or key words such as: ("emerg* technolog*" OR "technolog* emerg*") AND (educa* OR learn* OR teach* OR pedagog* OR student* OR formation OR instructi* OR school OR college OR university OR classroom).

In the Scopus database, the search was limited only to the title, abstract and the keywords, whilst Web of Science was limited by the subject. Both of them included the criteria of being articles of area of social sciences, the years of publication and the type of document.

\subsection{Phase 3: Search Debugging}

742 records were obtained in Scopus, 1035 were obtained in Web of Science, for a total of 1777. 266 of those records were duplicates, leaving a number of 1511. After that, the reading of the abstracts was carried out and 572 articles were accepted based on the inclusion criteria. Journals or conferences with less than three publications related to TEs and the educational field were excluded from that group, leaving a total of 288 articles to read and analyze.

\subsection{Phase 4: Coding and analysis of data}

As mentioned above, the analysis process was performed quantitatively and qualitatively according to the following categories: year of publication, type of document, objective or purposes of the research, study methodology, data collection instruments, affected population, skills or abilities, characteristics, ETs used and type of learning.

The studies were coded according to the previous categories through a content analysis in Microsoft Excel. It is important to mention that some studies were placed in more than one category due to their relevance; and the quantification of the data was performed after having read them all. 


\section{$3 \quad$ Results}

Initially, a quantitative analysis is presented to provide an overview of published studies according to the criteria: year of publication and type of document. Subsequently, the results of each of the research questions were presented quantitatively and qualitatively, based on the codification of the categories.

\subsection{Articles published per year}

Considering the 288 articles related to ETs in the field of formal education between 2006 and 2016, figure 1 shows that the number of publications year after year is maintained or grows relatively little. This suggests that the topic of ETs in the field of formal education has been a subject of interest by researchers in recent years.

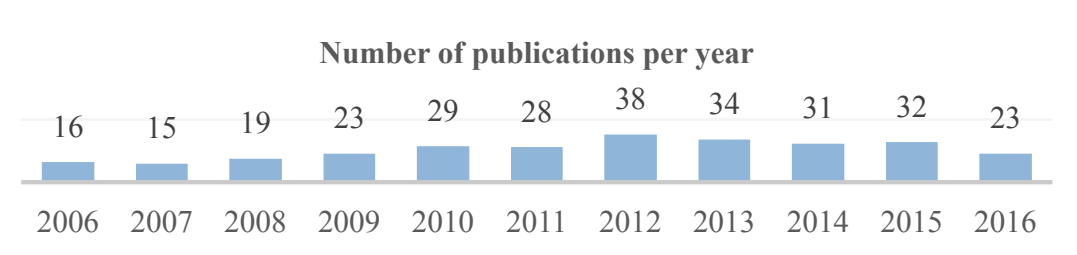

Fig. 1. Number of publications per year

\subsection{Type of document}

The type of documents that have been used to disseminate research and experiences related to the subject of this systematic review has been the conference papers, followed by articles, reviews and articles in press, as shown in figure 2.

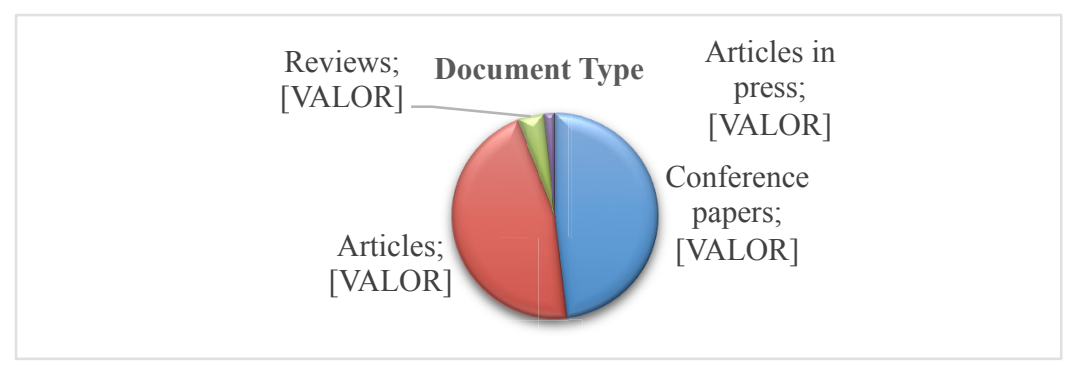

Fig. 2. Type of document

The results according to the research questions are presented below. 


\subsection{Research question 1: What are the objectives, methodologies, instruments of data collection and populations used in the studies related to the ETs in the field of formal education?}

Objectives: the studies in this review were initially classified into two fields; the general one $(80.2 \%, 231$ studies) and disciplinary one $(19.8 \%, 57$ studies). The general field refers to technologies such as mobile devices, web 2.0 technologies, augmented reality, etc., where the vast majority of the resources are oriented to describing, analyzing, understanding or proposing an effective and efficient use of ETs in the educational context from different perspectives. Finally, the disciplinary field refers to technologies such as nanotechnology, green energy, molecular biology, etc., and all of these focus mainly on teaching that particular technology. Regardless of the classification, all the studies aim to improve and transform different educational processes.

In the general field, it was found that there is a heterogeneity of the objectives, as shown in table 1 .

Table 1. Classification of general field studies

\begin{tabular}{|l|c|c|}
\hline \multicolumn{1}{|c|}{ Classification } & $\#$ & $\%$ \\
\hline General aspects & 69 & $29,9 \%$ \\
\hline Design & 37 & $16 \%$ \\
\hline Perceptions & 33 & $14,3 \%$ \\
\hline Evaluation & 31 & $13,4 \%$ \\
\hline Development & 29 & $12,6 \%$ \\
\hline Models/approaches/methodologies/ frameworks & 20 & $8,7 \%$ \\
\hline Teacher training & 12 & $5,2 \%$ \\
\hline
\end{tabular}

In general aspects, there is a group of studies that make evident the positive and negative factors of the incorporation of ETs in the educational context. Thus, $25.4 \%$ specify and describe the advantages/disadvantages or facilitators/barriers or limitations (e.g., [6]), 9\% only show the advantages (e.g., [7]), 3\% apart from describing the advantages, they provide recommendations (e.g., [8]), 17.9\% propose only recommendations (e.g., [9]), 4.5\% explore the benefits (e.g., [10]), 3\% understand the challenges (e.g., [11]) and 3\% justify the need to incorporate ETs in educational processes (e.g., [12]).

Another group of studies corresponding to this classification offers an X-ray of the current status of ETs (13.4\%), from systematic reviews (e.g., [13]) to the use of ETs by different participants in education (e.g., 14]). Additionally, 10.4\% describe how ETs is being used in teaching and learning processes (e.g., [15]).

Finally, it was found that $4.5 \%$ of the articles conceptualize the ETs from different visions (e.g., [3]); 3\% they evidence the change generated in educational processes by incorporating ETs (e.g., [16]); 1.5\% describe the evolution of ETs in the field of education [17]; $1.5 \%$ describe, interpret and explain the reflections teachers make about the use of ETs in teaching (e.g., [18]) and 3\% present the feelings experienced by different participants of the learning process when using ETs (e.g., [18]). 
37 studies were found in design. 78.4\% were designed to implement and evaluate the different strategies used to incorporate different ETs in the classroom (e.g., [19]), $16.2 \%$ only designed the incorporation strategy, $2.7 \%$ designed and implemented a strategy but did not evaluate it (e.g., [21]) and $2.7 \%$ designed a strategy which was not implemented but it was evaluated from the perspectives of a participant of the educative process (e.g., [22]).

In perceptions, 33 studies tried to identify and analyze the perceptions of use of the TE of different educational participants as students (e.g., [23]) and teachers (e.g., [24]).

31 studies were found in the evaluation and they were classified into two: $58.1 \%$ incorporate an ET and then evaluate the efficiency in the educational context from different learning and teaching processes (e.g., [25]) and $41.9 \%$ are responsible for generating strategies to evaluate a ET, for example the study of Ashford-Rowe and Holt [26] propose a matrix to determine which ET can be more effective within the institution to improve teaching and learning processes. The study by Steiner et al. [27] creates a framework for evaluating ETs and the Krusberg study [28] evaluates three ETs from the interdisciplinary perspective of the cognitive science.

29 studies were found in the development. They were classified into two groups: $82.8 \%$ developed applications using ETs. For example Kevan and Ryan [29] used the emerging technology (ET) API to generate applications for learning, Herrera et al., [30] designed mobile applications to improve generic competencies and Navarro et al. [31] developed serious games using open-source tools and $17.2 \%$ of the studies not only developed the application but also implemented and evaluated it (e.g., [32]).

20 studies were found in models, approaches, methodologies or frameworks. $25 \%$ develop or propose a model for incorporating ETs into the classroom (e.g., [33]); 10\% use existing models to incorporate ETs (e.g., [34]). In approaches $35 \%$ focus on studying new teaching approaches and this way guide the incorporation of ET (e.g., [35]). $20 \%$ generate frames for integrating or adopting ETs (e.g., [36]). In methodology, 5\% of the studies propose a methodology for the design, implementation and evaluation of resources (e.g., [37]) and 5\% only design a methodology to include ET in the educational context (e.g., [38]).

Finally, in the classification carried out in the general field, there are studies related to teacher training, of which $50 \%$ design a teacher training strategy to incorporate ETs in their educational practice (e.g., [39], [40]) and the other $50 \%$ not only design the strategy but also evaluate it (e.g., [41]).

In the disciplinary field, it was found a diversity of objectives, as shown in Table 2, the largest number of studies in the disciplinary field aim to design, implement and evaluate strategies for teaching of disciplinarian ETs (e.g., [42]), followed by those that demonstrate the need to update a different Curricula, according to the global needs and new competencies that students need to have in a changing work environment (e.g., [43]). Those related to the design of strategies for teaching ET disciplines are next. For instance, the study by Partido et al., [44] which teaches the use of the dental endoscope and Flynn and Katz [45] who design courses in disciplinary areas so that students learn to use ETs. In a smaller amount of studies appear the ones which use used disciplinary ETs, for example the use of the synthetic chemistry or the use of 
laboratories based on cyber-physical systems within the educative context; a disciplinary TE is developed (e.g., [46]); strategies are designed for teacher training in the use of disciplinary ETs in the classroom (e.g., [47]); the perceptions of different actors on the disciplinary TEs (e.g., [48]) are determined and describe the advantages, disadvantages, strengths or weaknesses of disciplinary ETs.

Table 2. Objectives of the disciplinary field studies

\begin{tabular}{|l|c|c|}
\hline \multicolumn{1}{|c|}{ Objectives } & $\#$ & $\%$ \\
\hline Design, implement and evaluate strategies for teaching of disciplinarian Ets & 24 & $42.1 \%$ \\
\hline Curriculum - Need to update & 13 & $22.8 \%$ \\
\hline Design of strategies for teaching ET & 7 & $12.3 \%$ \\
\hline Used disciplinary ETs & 4 & $7.0 \%$ \\
\hline Development of ETs & 3 & $5.3 \%$ \\
\hline Teacher training & 2 & $3.5 \%$ \\
\hline Perceptions & 2 & $3.5 \%$ \\
\hline Advantages/disadvantages, strengths/weaknesses & 2 & $3.5 \%$ \\
\hline
\end{tabular}

Research methodology: From 288 studies, only 37.5\% (108) used a quantitative, qualitative or mixed research methodology, as presented in figure 3 .

\section{Research Methodology}

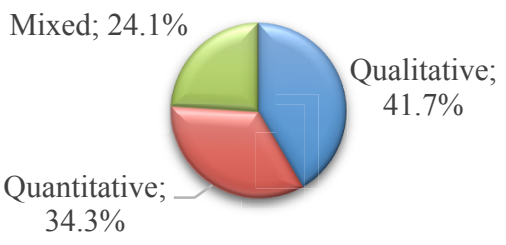

Fig. 3. Research Methodology

Within qualitative research, the case study was the most widely used (e.g., [7]), followed by design-based research [36], then there is a great diversity in methodologies such as action research, literature review, phenomenological studies, ethnographic studies, among others, which were not used by more than 4 studies.

In quantitative studies the experimental method was the most widely used (e.g., [44]), followed by the quasi-experimental method (e.g., [49]), other studies use an exploratory [50] and descriptive scope [51]. In mixed studies the quasi-experimental method was the most widely used (e.g., [52]), followed by the case study (e.g., [15], [42]).

Data collection instruments: Table 3 shows the instruments used to collect information. It is important to clarify that the total does not correspond to the total number of studies, because this study used several instruments for data collection (e.g., [50], [9]). 
Table 3. Data collection instruments

\begin{tabular}{|l|c|c|}
\hline \multicolumn{1}{c|}{ Instruments } & $\#$ & \% \\
\hline Survey & 84 & $36.5 \%$ \\
\hline Interview & 38 & $16.5 \%$ \\
\hline Observation & 31 & $13.5 \%$ \\
\hline Questionnaire & 21 & $9.1 \%$ \\
\hline Products generated & 20 & $8.7 \%$ \\
\hline Pre - post test & 19 & $8.3 \%$ \\
\hline Focus groups & 14 & $6.1 \%$ \\
\hline Rubrics & 3 & $1.3 \%$ \\
\hline
\end{tabular}

Table 3 shows that the survey is the main instrument of data collection, followed by the interview (semi-structured, structured) and then, the observation (participant and non-participant). On the other hand, the questionnaire, the products generated within the research by some of the participants of the educational process, the prepost test and the focus groups were used to a lesser extent and finally studies were found that used rubrics to collect information (e.g., [51])

Populations: initially, the articles were cataloged according to the educational context of the application in order to classify the affected population found in the studies. These were divided into primary education, secondary education, tertiary education (higher education) or some combination. A Context of general application that can be used at any educational level was found. Figure 4 shows the educational context of the 288 articles.

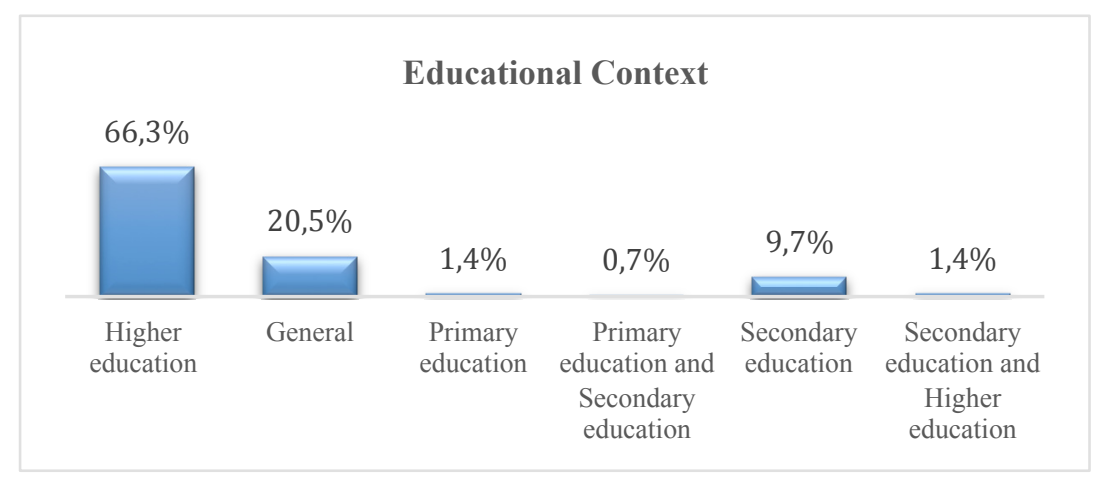

Fig. 4. Educational Context

As shown in Figure 4, 66.3\% of the studies have their context of application in higher education and correspond to undergraduate, specializations, masters and doctorates (e.g., [41]); 20.5\% are general context, meaning that their objectives and results can be used at any educational level (e.g., [53]); 9.7\% are from the context of secondary education and belong to levels from high school to k-12 (e.g., [19]); 1.4\% corresponds to the context of primary (pre-school, first, second, third, fourth and fifth education) (e.g., [9]); additionally, the $1.4 \%$ belongs to secondary and higher 
education (e.g., [25]) and $0.7 \%$ between primary and secondary education (e.g., [39]). The latter two percentages mean that the affected population is from both types.

Once the studies were classified according to the educational context of application, they were related to the type of population. The largest number of studies affected students of higher education, followed by students in secondary, general, primary and secondary and higher education, in this classification are students with special needs (e.g., [54]) and future teachers (e.g., [22]). In a smaller amount, the general population appears and as stated above, it means that its objectives and results can be applied in any population (e.g., [35]).A number of studies have also affected higher education teachers (e.g., [41], [15]), secondary (e.g., [47]), primary (e.g., [9]) and general context ], [33]). Additionally, we found 2 studies that affect the institution and 1 that is related to the instructional designer, as shown in table 4.

Table 4. Type of affected population

\begin{tabular}{|c|c|c|c|c|c|c|c|c|c|c|c|c|}
\hline \multirow{3}{*}{$\begin{array}{c}\text { Educational } \\
\text { Context }\end{array}$} & \multicolumn{12}{|c|}{ Affected population } \\
\hline & \multicolumn{2}{|c|}{$\begin{array}{c}\text { Instructional } \\
\text { designer }\end{array}$} & \multicolumn{2}{|c|}{ Teachers } & \multicolumn{2}{|c|}{ Students } & \multicolumn{2}{|c|}{$\begin{array}{c}\text { Students and } \\
\text { teachers }\end{array}$} & \multicolumn{2}{|c|}{ General } & \multicolumn{2}{|c|}{ Institution } \\
\hline & \# & $\%$ & $\#$ & $\%$ & \# & $\%$ & $\#$ & $\%$ & \# & $\%$ & \#. & $\%$ \\
\hline $\begin{array}{l}\text { Higher } \\
\text { education }\end{array}$ & 1 & $0.3 \%$ & 28 & $9.7 \%$ & 117 & $40.6 \%$ & 14 & $4.9 \%$ & 30 & $10.4 \%$ & 1 & $0.3 \%$ \\
\hline General & & & 9 & $3.1 \%$ & 13 & $4.5 \%$ & 2 & $0.7 \%$ & 34 & $11.8 \%$ & 1 & $0.3 \%$ \\
\hline Primary & & & & & 3 & $1.0 \%$ & & & 1 & $0.3 \%$ & & \\
\hline $\begin{array}{l}\text { Primary and } \\
\text { Secondary }\end{array}$ & & & 1 & $0.3 \%$ & & & 1 & $0.3 \%$ & & & & \\
\hline Secondary & & & 7 & $2.4 \%$ & 16 & $5.6 \%$ & 3 & $1.0 \%$ & 2 & $0.7 \%$ & & \\
\hline $\begin{array}{l}\text { Secondary } \\
\text { and Higher } \\
\text { education }\end{array}$ & & & 1 & $0.3 \%$ & 3 & $1.0 \%$ & & & & & & \\
\hline Total & 1 & $0.3 \%$ & 46 & $16.0 \%$ & 152 & $52.8 \%$ & 20 & $6.9 \%$ & 67 & $23.3 \%$ & 2 & $0.7 \%$ \\
\hline
\end{tabular}

\subsection{Research question 2: What competences or skills do you want to improve when incorporating ETs in the classroom?}

Regardless of population type, the competencies or skills that aimed to be improved by incorporating ETs in the classroom were: critical thinking $20.5 \%$ (e.g., [52]); 15.9\% problem solving (e.g., [55]); 15.9\% collaborative work (e.g., [56]); $13.6 \%$ communicative competence (e.g., [45]); 9.1\% creative thinking (e.g., [57]); $6.8 \%$ decision making (e.g., [55]) The competences or skills rarely used in the studies are: learning to learn; disciplinary skills; interpersonal skills; spatial thinking; a second language acquisition; skills specifically in the use of ETs; higher order skills and overall skills, each one represents $2.3 \%$ of the studies. It is important to mention that not all the studies tried to improve competences or skills. In this section, only those where the author explicitly or implicitly mentioned the competence or ability to improve are considered. 


\subsection{Research question 3: What are the characteristics of the ETs?}

As in the previous section, only those studies where the author explicitly or implicitly mentioned some characteristics of the ETs were placed in this space, we found 13 characteristics, as described below:

The most mentioned characteristic was that the ETs are contextual, that means they depend on the context (e.g., [5]), which implies that a technology is emerging when it is used in a context for the first time or it is being used in a new Way [24].

According to the above mentioned characteristics, an ET is not necessarily new [3] and what is emerging in one context may have already been used in another. Another characteristic is the ability of ETs to be adapted according to the context [56] and the context has to be adapted to the technology. This characteristic allows the participants of the educative process to generate different strategies of incorporation of technology in the classroom. Because of motivations or interests, ETs can be adapted to improve various educational processes depending on the needs.

The ETs and the forms of incorporation also evolve. They are continuously changing and updating according to the context (e.g., [13], [24]). This characteristic generates challenges like training the participants of the learning process in the use of ETs and thus, get the best from them. ETs are ubiquitous (e.g., [33]), they are present everywhere and overcome spatio-temporal constraints [20].

In addition, ETs are disruptive (e.g., [58]), that is, they have the ability to disrupt the educational context and change or update educational practices for the benefit of learning and teaching. This leads to another characteristic, they are innovative [59]) because they produce changes or transformations in the school from different processes. Besides, ETs are complementary in educational processes (e.g., [55]) by providing new forms of teaching for students to acquire the necessary skills to develop in this globalized world.

ETs generate a degree of uncertainty regarding their use (e.g., [48]), this feature is generally associated with failure to incorporate ETs into the classroom, by not being sure if its use will effectively improve educational processes. Also ETs are complex (e.g., [60]) because of a process of constant reflection on the advantages of using them in a particular context.

Finally, other authors mentioned that ETs should be accessible, functional, easy to use and interactive to achieve changes in the classroom; and regardless of the ETs, these should generate: motivation [32]; Reflection [37]; Interaction [49]; Autonomy [19]; Feedback [42]; Improvement of competencies [39] in the educational context.

\subsection{Research question 4: What types of ETs are used in the educational field?}

As mentioned at the beginning of the results section, the ETs were classified in two: general ET and disciplinary ET. The findings corresponding to each one are presented as follows. Just as the previous question, it only relates the studies where the author mentions ET.

General ETs: Initially they were categorized in four aspects: the first one corresponds to the studies where a software is mentioned (computer programs); the second 
one is where the hardware (devices) is used; the third one is the combination of both software and hardware, and the last aspect is others. In Figure 5 we can see the distribution of each aspect.

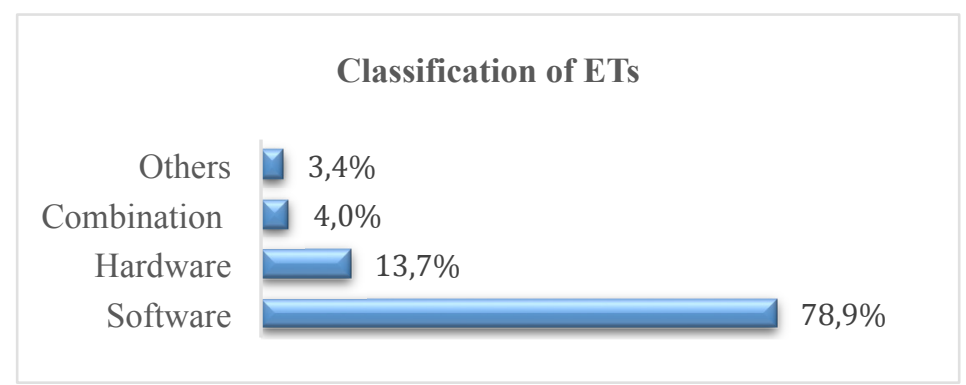

Fig. 5. Classification of ETs

In the software aspect, there are programs that allow users to perform a specific task. The most mentioned software was web 2.0 technologies (blogs, podcasts, social networks, among others) with 52.9\%. 16.9\% represent the programs that offer a direct or indirect real world view to users (virtual worlds, Virtual reality, etc.), $14.5 \%$ correspond to application programs (mobile applications, java script, html5, etc.), 9.8\% are educational platforms (LMS as Moodle), 3.1\% are games, Games on Facebook, etc.), $1.6 \%$ are educational resources (tutorials, open resources) and finally, $0.8 \%$ represent software that uses 3D technology (3D animations).

Within the Web 2.0 technologies it was found that: $43.7 \%$ are programs that are used to generate content in various formats: texts shared through google docs; Images as photojournal; audio through podcasts; video and shares via YouTube; multimedia like the construction of wikis in a collaborative way and finally, blogs to generate and transmit knowledge on behalf of students or teachers; $23.7 \%$ correspond to social networks; $12.6 \%$ generally refer to web 2.0 technologies; $8.1 \%$ are programs, such as Skype, chats, forums, text messages, among others, which allow communication between participants of the learning process; 5.9\% allows social bookmarking or social bookmarking like delicious and diigo; $2.2 \%$ combine several tools to create personal learning environments (PLE); $1.5 \%$ use digital portfolios to carry evidence; $0.7 \%$ represent the programs to save information as google drive; $0.7 \%$ uses various web 2.0 tools to generate learning communities; Finally $0.7 \%$ of the technologies of Web 2.0 correspond to programs that allow users to have updated information through the RSS.

Programs that allow a direct or indirect view of the real world are: $44.2 \%$ virtual worlds such as second life; $16.3 \%$ virtual laboratories; $11.6 \%$ the simulators; $11.6 \%$ is virtual reality technology; $9.3 \%$ immersion environments and $7 \%$ use immersion technology to improve educational processes.

In the application software, it is found that $70.3 \%$ are specific programs to perform some functions such as java script or scratch or programs to capture screen shots of what the student is doing for later assessment; $16.2 \%$ are programs to generate conferences or videoconferences and $13.5 \%$ are mobile applications. In educational plat- 
forms, $72 \%$ correspond to learning management systems (LMS) such as Moodle; $16 \%$ correspond to mass online courses (Moocs) and 12\% are technological, social and educational platforms such as Edmodo. Finally within the software aspect are games with $3.1 \%$, with $1.6 \%$ educational resources and $0.8 \%$ 3D Technology.

In the hardware aspect, there are the devices used in the studies. $79.5 \%$ are all mobile devices (smartphones, tablets, laptops); $6.8 \%$ correspond to devices that use 3D technology as $3 \mathrm{D}$ printers and $13.6 \%$ are other devices such as blackboards and multitouch tables.

In the combination of software and hardware, $76.9 \%$ corresponds to augmented reality studies and $23.1 \%$ to the use of programs and devices that use 3D technology.

In the other aspect, there are technologies that refer to innovations to improve learning and teaching processes, for example CALL (computer assisted language learning); Affective computing in learning; Learning analytics among other innovations.

Disciplinary ETs: Due to the diversity of the disciplinary ETs, they were classified according to the objectives mentioned in the finding of question 1 . The greatest number of ETs are found in the studies whose objective was to highlight the need to update the curricula to the current demands of the context. The technologies used in this objective were: Technical Animation; Software Engineering; Building Information Modeling (BIM); Instrumentation and Control; Biotechnology; Internet of Things; Trustworthy Computing; Interactive Multimedia; Entertainment Computing; Nanotechnology; Service Computing; Storage Area Networks; Grid Computing; Robotics; Ubiquitous computing; Automation; Biomedical equipment; Cyber-Physical Systems; Lean or advanced manufacturing; Mechatronic technology; Photonics; Proactive Environmental Management; Construction Graphics; Wireless sensor network (WSN) and Human-computer interaction (HCI) in the mobile environment.

The following technologies were used in the objective of designing, implementing and evaluating a strategy to teach a disciplinary ET: Bioengineering; Nanoelectronics; Cybernetics; Nanotechnology; Cloud Computing; Virtual Reality; Energy Harvesting; Wearable Technology; Home Automation; Software Defined Networking; Dental Endoscopy; Wireless Networks; Energy; Robotics; Molecular Genetic; Software Defined Radio (SDR); "Green" reinforced concrete structures; Electric vehicles; Wearables; Logic and the Energy harvesting for continuously powering sensor networks.

The ETs used for the design of teaching strategies are: Computer graphics; Composite materials; 3D Scanning; Microfluidics; Photonics; Sensors; Internet of Things; Web Technologies and Java. The Alternative Energy, Green Energy, Modern Manufacture, Nanotechnology and Fuel Cell were used to design teacher training strategies. Nanotechnology was used to look at perceptions about ET. The cone beam computed tomography and Emerging Writing Assessment Technologies were used to determine the advantages / disadvantages or strengths / weaknesses of these. Finally, the pocket labs based on cyber-physical systems and Synthetic chemistry were used within the educational context to improve some skills or competences. 


\section{Discussion and conclusions}

ETs, have been a subject of interest for researchers and teachers in formal education. This is due to the challenges that have existed and will exist in society in the educational field. One of these challenges has been the incorporation of Technology in order to improve the different educational processes; so the role of research in this field is to ensure the adoption of technologies for the transformation of educational practices [6], in addition, it is the responsibility of both researchers and teachers to communicate and publish their results and thus build and rebuild the field of educational technology. Thus, this systematic review reviewed, classified and analyzed studies related to emerging technologies in the field of education between 2006 and 2016 with the purpose of identifying areas of uncertainty for future research, and it is a tool for teachers to make decisions when incorporating technology in classrooms, taking into account the experiences of other people, based on a process of reflection on those studies in order to be able to generate their own strategies of incorporation. The following is the discussion, conclusions and some recommendations according to the findings found in each of the questions.

\subsection{About question 1}

All studies aimed to improve and transform the different educational processes through the incorporation of ET from two visions, one general and the other disciplinary: the first is oriented studies in describing, analyzing, understanding or proposing an effective and efficient use of ETs and the second focuses mainly on the teaching of disciplinary technologies. In general terms, the greatest number of studies are found due to the fact that there is significant commitment on behalf of the participants of the learning process to integrate ET into their educational processes. Following this line the studies that stand out are: studies that show the positive and negative factors of incorporation technology and the current state of the ET; the different strategies of incorporating ET in the classroom were designed, implemented and evaluated; perceptions about the use of ET were studied; the efficiency of the ETs was evaluated; ET was developed and subsequently applied; we described models, approaches and methodologies to incorporate ET, just like those related to the design of training strategies for teachers. In the disciplinary view, the studies stand out by: the design, implementation and evaluation of a strategy to teach a disciplinary ET and the need to update the curricula according to the changes of the context. In addition, all studies had two implicit purposes. The first one is to allow researchers and teachers not to start their research and implementations from scratch because they can learn from the successes and errors of these studies [62] and the second one is to improve the educational quality of the countries generating diverse strategies of incorporation of technology in the classroom.

It is evident that there is a great diversity of objectives related to the object of study of this systematic review. This does not mean that the issue is already solved. On the contrary, due to the social and technological changes it is necessary to continue investigating on the incorporation of ET in educational processes, either with the achieved 
goals or new ones as: generate new teaching methods [19]; design strategies for TE incorporation [29]; Develop new assessment tools [63]; generalize more the findings in different studies [16] among others. However, regardless of the purpose of the study, everyone should aim for good quality education for all.

As for the research methodology, the qualitative was the most used, followed by the quantitative and the mixed. Within the qualitative methodology, the study case was the most used because "it adapts to each reality and acquires specific modalities depending on its context and purpose" [64] in incorporating TE, but it has some disadvantages: its findings cannot be generalized and the subjectivity of the researcher in the results [64]. Design-based research was also used to establish "the relationships between educational theory, designed artifact and practice to improve learning, create useful knowledge, and advance the construction of theories about learning and teaching in environments Complex"[65] and especially in environments where technology is incorporated.

In the quantitative research, the experimental method was the most widely used, because it allowed researchers to compare between: conventional teaching methodologies and teaching methodologies using ET (e.g., [19]); Groups exposed to an ET and not exposed (e.g., [23]) and between conventional and ET technologies (e.g., [66]), one of the advantages of using the experimental method is that it allows researchers and teachers to determine whether the design and implementation of the strategy produces significant changes in the groups and thus, establish whether the incorporation of ET improves or not the educational processes through the use of statistics.

In mixed investigations, the quasi-experimental method was the most used. This may be because they are feasible, can be made in small units; facilitate the development of studies in natural environments and causal relationships and can be inferred among the variables investigated. Among its limitations, it was found population selection bias, due to the lack of randomization and the lack of control of unexpected variables that can alter the results of the study [67].

Regardless of the chosen research approach, it is necessary to carry out "systematic, critical and empirical processes that are applied to the study of a phenomenon or problem" [68] related to the incorporation of ET in educational processes to achieve validity in the educational community. It is recommended to consider longitudinal investigations to analyze the changes through time, because in this systematic review, the studies found were mainly transactional or transversal.

The instruments for data collection in this systematic review were 8 (surveys, interviews, observations, questionnaires, student generated products, pre-post tests, focus groups and rubrics), regardless of instrument, it is important to achieve a high degree of reliability, validity and objectivity because the analysis to reach the objectives of the investigation is based on the obtained data [68]. Likewise, the results obtained in this review confirm the findings of research on the review of trends in mobile learning studies, where most studies adopted the survey as the main tool for data collection [13].

On the other hand, the most affected population in the studies were the students and specifically the students of higher education. This may be because universities 
generate incentive plans for teachers, for publishing their studies (e.g., [69]), something that doesn't happen much in primary and secondary levels. For this reason policies must encourage more publication of experiences and research by teachers, in order to be able to find deeper studies related to the primary and secondary. It was also found that very few studies affect teachers, so it is necessary to carry out research where different training strategies are designed for the incorporation of ET, based on their own contextual needs, become aware of the new options provided by ET to improve the processes of teaching and learning [70] and reflect on their use in the classroom [71].

\subsection{About question 2}

According to the results obtained in this aspect, there is a concern regarding improvements or ways to strengthen the different abilities and competences of students and teachers, based on diverse strategies to apply ET in the classroom, especially those skills and competences of the 21 st century, such as critical thinking, problem solving, collaborative work, communicative competence, creative thinking, decisionmaking, among others, to learn, work and live efficiently and effectively in 21 st century [52].

On the other hand, the rapid changes of technology become a challenge for the participants of the learning process and the creation of innovating training plans to integrate new technologies [43]. Also, more training is needed regarding the skills needed to face the challenges and problems that emerge from a complex and changing world. In order to achieve the objectives, educators must develop lifelong learners who have the ability to innovatively apply competences to new situations [35].

\subsection{About question 3}

Technology is considered emergent if it has several characteristics, for example Veletsianos [3] described five and Backhouse [24] mentions 6, comparing the 2 previous authors and the findings of this study, they have 3 characteristics in common: to be contextual; to be continuously evolving and to be disturbing or disruptive. In this review we found 10 additional features: the ability to be adapted to the needs of the context; to be ubiquitous; Innovative; to have a degree of uncertainty regarding its use; to be complex; complementary; accessible; functional; easy to use and interactive.

On the other hand, Veletsians [3] stated that "ETs have not yet been understood and investigated enough". Taking into account that ET are contextual and the number of studies found in this review, this assertion is not necessarily truth, because there are researches carried out based on the design, development, implementation and evaluation that allow ET to be understood. Besides, due to technological advances, new technologies will always be a subject of investigations. This implies a challenge to researchers and teachers, which is carrying out studies to understand ET from different aspects. 


\subsection{About question 4}

In the review of the studies, a great diversity of ETs was found, but only two groups were highlighted. The first one corresponds to the software programs and the second to the devices (hardware). Both groups with the purpose of improving the educational processes. In the software web 2.0 technologies (blogs, wikis, social networks, etc.) were the most used because they are accessible and available at low costs and some applications are free, they are easy to implement and use, optimize time, access and navigation costs [72]. In the hardware, the mobile devices are the ones that stand out. This is because there has been an increase in the use of them by all educational participants and their characteristics such as portability, ubiquity and connectivity [73] allow to generate different strategies to incorporate these devices in different contexts.

It was also found that TE disciplines are developed for specific fields such as nanotechnology, green energy, biofuels, etc., and these are generating the need to update and create new curricula [74] to be in accordance with the new social challenges. In addition, teachers should design, implement and evaluate different teaching strategies related to the effective management of these technologies [42] so that students can use their skills and competencies in solving problems.

Finally, the findings found in this section demonstrate that TEs are not only devices but also refer to "tools, concepts, innovations and advances used in various educational contexts, with various teaching purposes" [3], For example, CALL (computer assisted language learning), affective computing, learning analytics are tools and innovations used by teachers to transform their educational practice.

\section{$5 \quad$ References}

[1] E. M. Garcia et al., Ciencia, Tecnología y Sociedad: una aproximación conceptual, ESP: Organización de Estados Iberoamericanos (OEI), 2001.

[2] G. S. Day and P. J. Schoemarker, "Avoiding the Pitfalls of Emerging Technologies," California Manage. Review, vol. 42, no. 2, pp. 8-33, Dec 2000. http://dx.doi.org/10.2307/41166030

[3] G. Veletsianos, "A Definition of Emerging Technologies for Education," in Emerging Technologies in Distance Educ., G. Veletsianos, Edmonton: AU Press, 2010, ch. 1, pp. 322. Available: http://www.aupress.ca/index.php/books/120177

[4] D. Rotolo et al., "What Is an Emerging Technology?," Research Policy, vol. 44, no. 10, pp. 1827-1843, Dec 2015. http://dx.doi.org/10.1016/j.respol.2015.06.006

[5] D. Kabugo et al., "A Discourse Analysis of Teacher-Trainees' Abstract Conceptualizations of Emerging Technologies in Teaching Luganda Language to the Digital Natives", in ICERI2015: 8th Int. Conf. Educ. Research and Innovation, Seville 2015, pp. 5989-6001. http://files.eric.ed.gov/fulltext/EJ1107341.pdf

[6] D. Ng'Ambi and V. Bozalek, "Leveraging informal leadership in higher education institutions: A case of diffusion of emerging technologies in a southern context," British J. of Educational Technology, vol. 44, no. 6, pp. 940-950, Nov 2013. http://dx.doi.org/10.1111/bjet.12108 
Paper-Emerging Technologies (ETs) in Education: A Systematic Review of the Literature Published...

[7] D. Churchill and N. Churchill, "Educational affordances of PDAs: A study of a teacher's exploration of this technology," Computers \& Education, vol. 50, no. 4, pp. 1439-1450, May 2008. http://dx.doi.org/10.1016/j.compedu.2007.01.002

[8] R. Godwin-Jones, "Emerging technologies: The technological imperative in teaching and learning less commonly taught languages," Language Learning \& Technology, vol. 17, no. 1, pp. 7-19, Feb 2013. http://1lt.msu.edu/issues/february2013/index.html

[9] S. C. Li et al., "Empowering student learning through tablet PCs: A case study," Education and Information Technologies, vol. 15, no. 3, pp. 171-180, Sept 2010. http://dx.doi.org/10.1007/s10639-009-9103-2

[10] Y. Beldarrain, "Distance education trends: Integrating new technologies to foster student interaction and collaboration," Distance Education, vol. 27, no. 2, pp. 139-153, Jan 2007. http://dx.doi.org/10.1080/01587910600789498

[11] N. Johnson and K. D. Joshi, "The pathway to enterprise mobile readiness: Analysis of perceptions, pressures, preparedness, and progression," in AMCIS 2012: 18th Americas Conf. Inform. Systems, Seattle, 2012, pp. 2517-2524. http://aisel.aisnet.org/cgi/viewcontent.cgi? article $=1234 \&$ context $=$ amcis 2012

[12] T. Andrews et al., "Rich media technologies and uncertain futures: Developing sustainable, scalable models," in ASCILITE 2008 - the Australasian Soc. for Comput. in Learning in Tertiary Educ., Melbourne, 2008, pp. 36-40. http://ro.uow.edu.au/cgi/viewcontent.cgi? article $=1394 \&$ context $=$ asdpapers

[13] W. Wu et al., "Review of trends from mobile learning studies: A meta-analysis," Computers \& Education, vol. 59, no. 2, pp. 817-827, Sept 2012. http://dx.doi.org/10.1016/j.comp edu.2012.03.016

[14] F. Tomos et al., "Technology Enhanced Learning at the University of Glamorgan with a Focus on Students' Mobile Technologies," in Proceess 11th European Conf. E-Learning, Groningen, 2012, pp. 661-664. https://goo.gl/ShNMO1

[15] V. Bozalek, "An investigation into the use of emerging technologies to transform teaching and learning across differently positioned higher education institutions in south Africa," in ASCILITE 2011 - the Australasian Soc. for Comp. in Learning in Tertiary Educ., Hobart, 2011, pp. 156-161. http://www.ascilite.org/conferences/hobart11/downloads/papers/ Bozalek-concise.pdf

[16] K. M. Scott, "Does a university teacher need to change e-learning beliefs and practices when using a social networking site? A longitudinal case study," British J. of Educational Technology, vol. 44, no. 4, pp. 571-580, Jun 2013. http://dx.doi.org/10.1111/bjet.12072

[17] A. F. O'Neil, "The current status of instructional design theories in relation to today's authoring systems," British J. of Educational Technology, vol. 39, no. 2, pp. 251-267, Mar 2008. http://dx.doi.org/10.1111/j.1467-8535.2008.00815.x

[18] D. Kabugo et al., "Scaffolding Teacher-Trainees' Reflective Observations About Utilizing Emerging Technologies in Teaching Luganda Language," in ICERI 2015: 8th Int. Conf. Educ. Research and Innovation, Seville, 2015, pp. 838-85. https://library.iated.org/view/KABUGO2015SCA

[19] E. Fokides and P. Atsikpasi, "Tablets in education. Results from the initiative ETiE, for teaching plants to primary school students," Educ. and Inform. Technologies, pp. 1-19, Nov 2016. http://dx.doi.org/10.1007/s10639-016-9560-3

[20] N. Amrous, "How to promote learning in african countries?," Int. J. Emerging Technologies in Learning, vol. 8, no. 4, pp. 40-46, Aug 2013. http://dx.doi.org/10.3991/ijet. v8i4.2725

[21] N. Filer and M. Demaidi, "Wireless Ray Tracing Educational Land," in INTED2012: Int. Technology, Educ. and Develop. Conf., Valencia, 2012, pp. 402-411. 
Paper-Emerging Technologies (ETs) in Education: A Systematic Review of the Literature Published...

https://www.researchgate.net/publication/260816961 Wireless ray tracing educational 1 and

[22] N. Alev et al., "Examining pre-service physics teachers' pedagogical content knowledge (PCK) with Web 2.0 through designing teaching activities," in 4th World Conf. Educ. Sciences (WCES), Barcelona, 2012, pp. 5040-5044. http://doi.org/10.1016/j.sbs pro.2012.06.383

[23] S. Downey et al., "Learner perceptions and recall of small group discussions within 2D and 3D collaborative environments," Australasian J. of Educational Technology, vol. 28, no. 8, pp. 1405-1419, 2012 http://dx.doi.org/10.14742/ajet.778

[24] J. Backhouse, "What makes lecturers in higher education use emerging technologies in their teaching?," Knowledge Manage. and E-Learning, vol.5, no. 3, pp. 345-358, Sep 2013. http://www.kmel-journal.org/ojs/index.php/online-publication/article/view/246/193

[25] E. K. H. Saitta et al., "Incorporating service-learning, technology, and research supportive teaching techniques into the university chemistry classroom," J. of Sci. Educ. and Technology, vol. 20, no. 6, pp. 790-795, Jan 2011. http://dx.doi.org/10.1007/s10956-010-92730

[26] K. H. Ashford-Rowe and M. Holt, "Emerging Educational Institutional Decision-Making Matrix," in INTED 2010:4th Int. Technology, Educ. and Develop. Conf., Valencia, 2010, pp. 2587-2593. https://eric.ed.gov/?id=ED519570

[27] C. M. Steiner et al., "Evaluation of Serious Games: A Holistic Approach," in ICERI2015: 8th Int. Conf. Educ., Research and Innovation, Seville, 2015, pp. 4334-4342. https://www.researchgate.net/profile/P Hollins/publication/284719660 Evaluation of Ser ious Games A Holistic Approach/links/56570a9108ae1ef9297b8fe5.pdf?origin=publicat ion list

[28] Z. A. C. Krusberg, "Emerging technologies in physics education," J. of Sci. Educ. and Technology, vol. 16, no. 5, pp. 401-411, Jun 2007. http://dx.doi.org/10.1007/s10956-0079068-0

[29] J. M. Kevan and P. R. Ryan, "Experience API: Flexible, decentralized and activity-centric data collection," Technology, Knowledge and Learning, vol. 21, no. 1, pp. 143-149, May 2016. http://dx.doi.org/10.1007/s10758-015-9260-x

[30] S. I. Herrera et al., "Mobile technologies in engineering education," in ICL 2015: Proc. 2015 Int. Conf. Interactive Collaborative Learning, Florence, 2015, pp. 1157-1164. http://dx.doi.org/10.1109/ICL.2015.7318197

[31] A. Navarro et al., "Work in progress - serious 3D game for mobile networks planning," in 2010 IEEE FIE: Proc. - Frontiers in Educ. Conf., 2010, pp. T1F1-T1F2. http://dx.doi.org/10.1109/FIE.2010.5673539

[32] M. E. C. Santos et al., "Evaluating augmented reality for situated vocabulary learning," in ICCE 2014:Proc. 22nd Int. Conf. Comput. in Educ., Nara, 2014, pp. 701-710. https://www.academia.edu/8572119/Evaluating Augmented Reality for Situated Vocab ulary Learning

[33] C. Holotescu, "A conceptual model for Open Learning Environments," in Proc. 10th Int. Conf. Virtual Learning, Timisoara, 2015, pp. 54-61. https://www.researchgate.net/publi cation/282158171 A conceptual model for Open Learning Environments

[34] J. H. Sharp, "Development, extension, and application: A review of the technology acceptance model," in ISECON: Proc. Inform. Syst. Educ. Conf., Dallas, 2006, pp. 1 - 9. https://pdfs.semanticscholar.org/4edf/4fc0bcf86d6fd165c22054d093e687fc1faf.pdf

[35] L. M. Blaschke, "Heutagogy and lifelong learning: A review of heutagogical practice and self-determined learning," Int. Review of Research in Open and Distance Learning, vol. 
Paper-Emerging Technologies (ETs) in Education: A Systematic Review of the Literature Published...

13, no. 1, pp. 56-71, Jan 2012. http://www.irrodl.org/index.php/irrodl/ article/view/1076/2087

[36] I. Tarling and D. Ng'ambi, "Teachers pedagogical change framework: A diagnostic tool for changing teachers' uses of emerging technologies," British J. of Educational Technology, vol. 47, no. 3, pp. 554-572, Apr 2016. http://dx.doi.org/10.1111/bjet.12454

[37] A. Mikroyannidis et al., "Applying a methodology for the design, delivery and evaluation of learning resources for remote experimentation," in IEEE Global Engineering Educ. Conf. EDUCON, Abu Dhabi, 2016, pp. 448-454. http://dx.doi.org/10.1109/EDU CON.2016.7474592

[38] J. Herrington and J. Parker, J. "Emerging technologies as cognitive tools for authentic learning," British J. of Educ. Technology, vol. 44, no. 4, pp. 607-615, Jun 2013. http://dx.doi.org/10.1111/bjet.12048

[39] M. Pérez-García, "MUVEnation: A european peer-to-peer learning programme for teacher training in the use of MUVEs in education," British J. of Educational Technology, vol. 40, no. 3, pp. 561-567, Apr 2009. http://dx.doi.org/10.1111/j.1467-8535.2009.00951.x

[40] K. Smyth, "Transformative online education for educators: Cascading progressive practice in teaching, learning and technology," in ECEL 2009: 8th European Conf. eLearning 2009, Bari, 2009, pp. 549-557. http://connection.ebscohost.com/c/articles/48966870/ transformative-online-education-educators-cascading-progressive-practice-teachinglearning-technology

[41] K. Singh, "Blended professional learning - modelling the paradigm shift," in Proc. ASCILITE 2014 - Annu. Conf. Australian Soc. for Comput. in Tertiary Educ., Dunedin, 2014, pp. 404-409. http://www.ascilite.org/conferences/dunedin2014/files/concisepapers/ 61-Singh.pdf

[42] A. C. Taylor, "Use of Case Studies and a Systematic Analysis Tool to Engage Undergraduate Bioengineering Students in Ethics Education," in 2012 ASEE Annu. Conf., San Antonio, 2012, pp. 1-16. https://www.asee.org/public/conferences/8/papers/3061/view

[43] D. Newberry and M. Barger, "Modularizing Emerging Technology Education: Two Case Studies," in 2013 ASEE Ann. Conf., Atlanta, 2013, pp. 1-12. https://www.asee.org/public/conferences/20/papers/6784/view

[44] B. B. Partido et al., "Calculus detection calibration among dental hygiene faculty members utilizing dental endoscopy: A pilot study," J. of Dental Educ., vol. 79, no. 2, pp. 124-132, Feb 2015. https://www.ncbi.nlm.nih.gov/pubmed/25640616

[45] J. Flynn and S. Katz, "Using Software Defined Radio for Multidisciplinary Senior Design Projects," in 2011 ASEE Annu. Conf. \& Expo., Vancouver, 2011, pp. 1-11. https://peer.asee.org/using-software-defined-radio-for-multidisciplinary-senior-designprojects

[46] M. Gusev et al., "E-learning and benchmarking platform for parallel and distributed computing," Int. J. of Emerging Technologies in Learning, vol. 9, no. 2, pp. 7-21, Mar 2014. http://dx.doi.org/10.3991/ijet.v9i2.3215

[47] L. Guo and M. Tahernezhadi, "Emerging Technology Institute - Training Middle and High School Teachers in Alternative Energy," in 2011 ASEE Annu. Conf. \& Expo., Vancouver, 2011, pp. 1-7 https://www.asee.org/public/conferences/1/papers/270/view

[48] G. E. Gardner et al., "Factors influencing postsecondary STEM students' views of the public communication of an emergent technology: A cross-national study from five universities," Research in Sci. Educ., pp.1-19, Oct 2016. http://dx.doi.org/10.1007/s11165-016$\underline{9537-7}$ 
Paper-Emerging Technologies (ETs) in Education: A Systematic Review of the Literature Published...

[49] L. A. Annetta, "Investigating the impact of video games on high school students' engagement and learning about genetics," Computers and Education, vol. 53, no. 1, pp. 74-85, Aug 2009. http://dx.doi.org/10.1016/j.compedu.2008.12.020

[50] D. Gachago et al., "Podcasts: A technology for all?," British J. of Educational Technology, vol. 47, no. 5, pp. 859-872, Jul 2016. http://dx.doi.org/10.1111/bjet.12483

[51] S. Pedersen and T. Irby. "The VELscience project: Middle schoolers' engagement in student-directed inquiry within a virtual environment for learning," Computers and Education, vol. 71, pp. 33-42, Feb 2014. http://dx.doi.org/10.1016/j.compedu.2013.09.006

[52] H. P. McKenna and S. A. Chauncey, "Taking Learning to the City: An Exploration of the Frictionless Learning Environment Innovation," in EDULEARN14: 6th Int. Conf. Educ. and New Learning Technologies, Barcelona, 2014, pp. 324-6334. https://library.iated.org/view/MCKENNA2014TAK

[53] C. Wu et al., "Review of affective computing in education/learning: Trends and challenges," British J.of Educational Technology, vol. 47, no. 6, pp. 1304-1323, Aug 2016. http://dx.doi.org/10.1111/bjet.12324

[54] K. Bain et al., "Transcribe Your Class: Empowering Students, Instructors, and Institutions: Factors Affecting Implementation and Adoption of a Hosted Transcription Service". In INTED 2012: Int. Technology, Educ. and Develop. Conf., Valencia, 2012, pp. 1446-1454. https://library.iated.org/view/BAIN2012TRA

[55] J. Phillips and Z. L. Berge, Z. L. "Second life for dental education," J. of Dental Education, vol. 73, no. 11, pp. 1260-1264, Nov 2009. https://www.ncbi.nlm.nih.gov/ pubmed/19910474

[56] C. Roche, "Formative Assessment for 'Graduate Attributes': Technology-Enhanced Learning in the First Semester," in EDULEARN12: 4th Int. Conf. Educ. and New Learning Technologies, Barcelona, 2012, pp. 5129-5137. https://library.iated.org/view/ROCHE20 $12 \mathrm{FOR}$

[57] H. P. McKenna et al., "Application of the Consensual Assessment Technique In 21st Century Technology-Pervasive Learning Environments," in 6th Int. Conf. Educ., Research and Innovation (ICERI 2013), Seville, 2013, pp. 6410-6419. https://library.iated.org/view/MCKENNA2013APP

[58] T. A. Koszalka and G. S. Ntloedibe-Kuswani, "Literature on the safe and disruptive learning potential of mobile technologies," Distance Education, vol. 31, no. 2, pp. 139-157, Jul 2010. http://dx.doi.org/10.1080/01587919.2010.498082

[59] D. L. McEachron et al., "Digital socrates: A system for disseminating and evaluating best practices in education," Campus-Wide Information Systems, vol. 29, no. 4, pp. 226-237, 2012. http://dx.doi.org/10.1108/10650741211253822

[60] T. M. Winge and M. C. Embry, "Fashion design podcast initiative: Emerging technologies and fashion design teaching strategies," in Increasing Student Engagement and Retention Using Mobile Applications: Smartphones, Skype and Texting Technologies (Cutting-edge Technologies in Higher Education), L. A. Wankel and P. Blessinger (ed.), vol. 6, USA: Emerald Group Publishing Limited, 2013, pp. 145-174. http://dx.doi.org/10.1108/S20449968(2013)000006D008

[61] F. Bell, "Connectivism: Its place in theory-informed research and innovation in technology-enabled learning," Int. Review of Research in Open and Distance Learning, vol. 12, no. 3, pp. 98-118, Mar 2011. http://www.irrodl.org/index.php/irrodl/article/view/902/1664

[62] S. A. Williams et al., "RedGloo: Experiences of developing and using an emerging technology in higher education," British J. of Educational Technology, vol. 44, no. 4, pp. 668670, Jun 2013. http://dx.doi.org/10.1111/bjet.12055 
Paper-Emerging Technologies (ETs) in Education: A Systematic Review of the Literature Published...

[63] J. A. Morrow et al., "Effective use of e-grading in the dental simulation clinic," J. of Dental Education, vol. 78, no. 6, pp. 829-837, Jun 2014. https://www.ncbi.nlm.nih.gov/ pubmed $/ 24882768$

[64] C. Álvarez and J. San Fabián, "La elección del estudio de caso en investigación educativa," Gazeta de Antropología, vol. 28, no. 1, pp. 1-12, Jun 2012. http://hdl.handle.net/10481/20644

[65] Design-Based Research Collective, "Design-based research: An emerging paradigm for educational inquiry," Educational Researcher, vol. 32, no. 1, pp. 5-8, Jan 2003. http://dx.doi.org/10.3102/0013189X032001005

[66] K. Pyatt and R. Sims, "Learner performance and attitudes in traditional versus simulated laboratory experiences," in ASCILITE 2007 - the Australasian Soc. for Comp. in Learning in Tertiary Educ., Singapore, 2007, pp. 870-879. http://www.ascilite.org/conferences/ singapore $07 /$ procs/pyatt.pdf

[67] A. Segura, (2003, Jul). Diseños Cuasiexperimentales. [Online] Available: http://www.sld.cu/galerias/pdf/sitios/renacip/disenos cuasiexperimentales.pdf

[68] R. Hernández et al., Metodología de la investigación, 6th ed. México: McGrawHill, 2014.

[69] Universidad del Rosario. (2006, Mar 14). Incentivos Económicos en Proyectos de Investigación, Asesoría y Consultoría. [Online]. Available: http://www.urosario.edu.co/Profeso res/ur/Incentivos-por-produccion-academica/

[70] R. Godwin-Jones, "Emerging Technologies the Evolving Roles of Language Teachers: Trained Coders, Local Researchers, Global Citizens," Language, Learning and Technology, vol. 19, no. 1, pp. 10-22, Feb 2015. http://1t.msu.edu/issues/february 2015/emerging.pdf

[71] M. Schols, "Examining and understanding transformative learning to foster technology professional development in higher education," Int. J. Emerging Technologies in Learning, vol. 7, no. 1, pp. 42-49, Oct 2012. http://dx.doi.org/10.3991/ijet.v7i1.1764

[72] D. Rodríguez. (2008, Jun). Nuevas tecnologías Web 2.0: Hacia una real democratización de la información y el conocimiento. [Online]. Available: http://eprints.rclis.org/11814/1/ Rodriguez-DianaTRABAJOelis.pdf

[73] C. Cantillo et al. (2012, Jun) Tendencias actuales en el uso de dispositivos móviles en educación, la educación digital Magazine. [Online]. Available: http://educoas.org/portal/ la educacion digital/147/pdf/ART UNNED EN.pdf

[74] D. M. Hull and C. A. Panayiotou, "Systems Technicians: Electronics Foundation with Photonics, Robotics and Other Specialties," in 2014 ASEE Annu. Conf., Indianapolis, 2014, pp. 24.1151.1 - 24.1151.9. https://peer.asee.org/systems-technicians-electronicsfoundation-with-photonics-robotics-and-other-specialties

[75] J. Sancho, "Jóvenes investigadores en TIC. De los temas de estudio a la carrera académica," Fuentes: Revista de la Facultad de Ciencias de la Educación, vol. 13, pp. 79-92, Jun 2013. http://hdl.handle.net/11441/33667

[76] B. Gros, "De cómo la tecnología no logra integrarse en la escuela a menos que.... cambie la escuela" in Experiències d'ús de les TIC a l'ensenyament Jornada Espiral 2004, 2004, pp. 1-9. http://ciberespiral.net/index.php\%3Foption=com content\&task=view\&id=59\& Itemid $=47 . \mathrm{html}$ 


\section{Authors}

Edgar Andres Sosa Neira, PhD student in Educational Technology from University of the Balearic Islands (UIB - Spain), master in Educational Informatics from University of La Sabana (Colombia), currently serving as a lecturer at the District Education of Secretariat (Bogotá), researcher and teacher at the Autonomous University of Manizales. Belonging to the District Network of Research Teachers and interested in Educational Technology research.

Jesus Salinas received his PhD from the University of Balearic Islands (UIB), Spain. Director of the Institute of Research and Innovation in Education, professor of Educational Technology and senior researcher in the Educational Technology Group. Director of Edutec-e Electronic Journal of Educational Technology, and consultant for several universities in different countries on issues of technology integration in higher education. His research interest includes E-Learning, Self-Regulated ELearning, E-Learning Design, online PhD supervision, and Personal Learning Environments.

Barbara de Benito Crosetti is lecturer of Educational Technology at the University of Balearic Islands (UIB). Researcher at Education Technology Group from UIB, since its creation in 1992, working in R+D projects. Founder member and advisor to the spin-off Zairja, S.L. (Training and Knowledge Management Solutions). Member of EDUTEC (Association for the development of education technology). Member of Congress Scientific Committees associated with Education Technology, e-learning, distance learning, etc (eg, EDUTEC, IADIS). Has written various articles and made contributions at conferences on Education Technology.

Article submitted 21 March 2017. Published as resubmitted by the authors 28 April 2017. 